\title{
Hyaluronic Acid of Low Molecular Weight Triggers the Invasive "Hummingbird" Phenotype on Gastric Cancer Cells
}

\author{
Sara Amorim,* Diana Soares da Costa, Iva Pashkuleva, Celso A. Reis, Rui L. Reis, \\ and Ricardo A. Pires*
}

The overproduction and deposition of hyaluronic acid (HA) of different sizes in the tumor microenvironment is associated with cancer metastasis. Here, the development of layer-by-layer ( $L b L$ ) constructs containing HA of different molecular weights (i.e., 5.6, 618, and $1450 \mathrm{kDa}$ ) that mimic the HA-rich cancer extracellular matrix is described to study the effect of the HA's size on the behavior of gastric cancer cells (ACS). The results demonstrate that LbL constructs with short $\mathrm{HA}$, i.e., $5.6 \mathrm{kDa}$, activate the cytoskeleton rearrangement leading to the "hummingbird" morphology, promote high cellular motility, and activate signaling pathways with increased expression of p-ERK1/2 and p-AKT. In addition, it is demonstrated that this malignant transformation involves an active participation of the HA coreceptor RHAMM in AGS cells.

\section{Introduction}

Gastric cancer (GC) is one of the leading causes of cancer-related deaths. ${ }^{[1]}$ Its onset and progression are commonly associated with the infection by the Gram-negative bacterium Helicobacter pylori. Approximately half of the World's population is colonized with this bacterium, however, the majority of the individuals are asymptomatic. ${ }^{[2]}$ The long-term infection with $H$. pylori in combination with other factors, such as genetic background and dietary habits, among others, can potentiate gastric carcinogenesis. ${ }^{[3]}$ The most severe GC outcomes are usually related with the translocation of the cytotoxin-associated gene A antigen (CagA) from the H. pylori to the host epithelial cells through the cag pathogenicity island (PAI). ${ }^{[4]}$ The presence of the oncoprotein CagA in the epithelial cell membrane and its phosphorylation induce an elongation of epithelial GC cells to an "hummingbird"-like shape that is usually associated with the epithelial mesenchymal transition (EMT)..$^{[5]}$ In EMT the epithelial cells gain a mesenchymal character, lose cell-cell contacts and increase their migration and invasive capacity. ${ }^{[6]}$

Hyaluronic acid (HA) is one of the most abundant glycosaminoglycans (GAGs) in the extracellular matrix (ECM). Structurally, this is the simplest GAG as it is composed by repeating disaccharides of $\mathrm{N}$-acetylglucosamine and glucuronic acid. Besides this simple composition, HA is involved in different signaling pathways and thus, able to modulate pathological and physiological processes. An example is cancer cell behavior, which depends on HA size: short HA $(<100 \mathrm{kDa})$ is linked to cancer progression and poor GC prognosis; ${ }^{[7]}$ while long HA is associated with cancer latency. ${ }^{[8]}$ The main cell surface receptor for HA, the transmembrane protein CD44, is also a GC stem cell marker associated with cancer cell proliferation. ${ }^{[9]}$ Considering these HA bioactivities, we developed a 2D platform to assess the impact of HA size on the formation of an invasive "hummingbird" phenotype on the AGS cell line (derived from a GC). We built layer-by-layer (LbL) constructs through the sequential deposition of five bilayers made of poly-i-lysine (PLL, a polycation) and HA (a polyanion) of different sizes. ${ }^{[10]}$ In all generated constructs, (PLL-HA) $)_{5}$, the final surfaceexposed layer is made of HA. GC cells were seeded on these constructs and the influence of the HA size on the transition to

DOI: 10.1002/adbi.202000122 


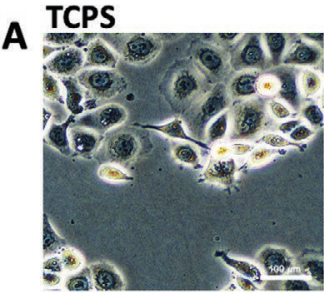

HA5.6

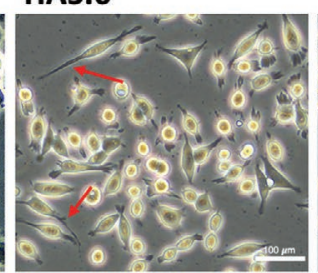

HA618

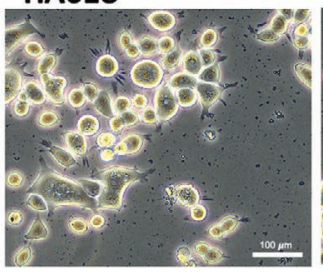

HA1450

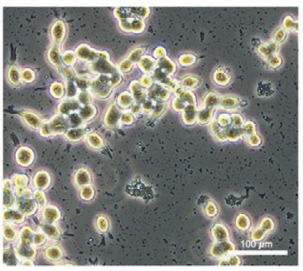

Hummingbird phenotype
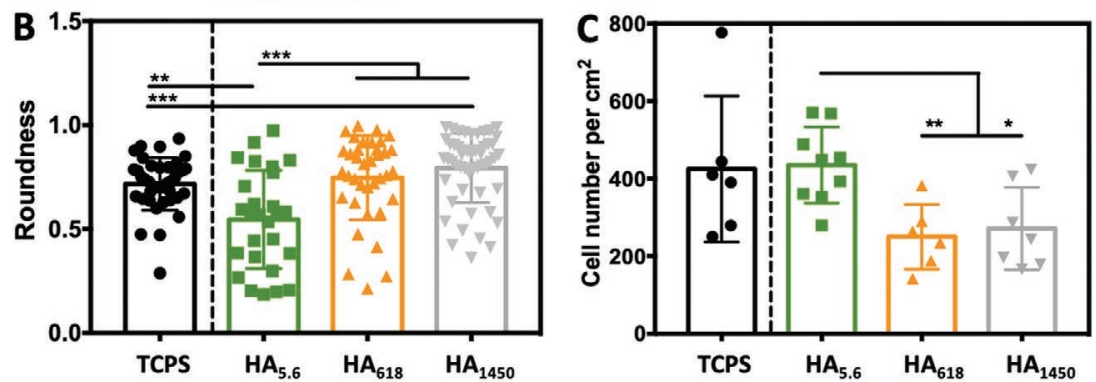

Figure 1. Transmission light microscopic images showing the morphology A) of ACS cells seeded on the LbL surfaces presenting HA of different $M_{w}$ i.e., 5.6, 618, and $1450 \mathrm{kDa}$. Morphometric analysis B) and number C) of the cells cultured under the same experimental conditions as in (A). Scale bars correspond to $100 \mu \mathrm{m}$. The data presented in the graphics correspond to the mean \pm SD calculated from a sample size of $n \geq 25$. Statistical significance was calculated using the Mann-Whitney test. Statistical differences are marked with $* * * *$ for $p<0.001$, ** for $p<0.01$, and $*$ for $p<0.05$.

the "hummingbird" phenotype and its link to GC invasiveness was investigated.

\section{Results and Discussion}

\subsection{Hummingbird Phenotype in the Presence of HA of Low $M_{\mathrm{w}}$}

To evaluate the influence of the HA's molecular weight $\left(M_{\mathrm{w}}\right)$ on the cellular morphology we cultured AGS cells on the $(\mathrm{PLL}-\mathrm{HA})_{5}$ LbL constructs generated using HA of 5.6, 618, and $1450 \mathrm{kDa}$ (Figure 1). We observe clear morphological differences between AGS cells cultured on the LbL with the shortest HA, i.e., $5.6 \mathrm{kDa}$, that exhibited a spindle-like shape typical of the "hummingbird" phenotype ${ }^{[5 a, 11]}$ and the other constructs presenting HA of higher $M_{\mathrm{w}}$ (Figure 1A) for which round cells were observed (Figure 1B). Of note, multinucleated giant cells (MGC), typical for AGS cultures, were observed on the control surface (i.e., tissue culture polystyrene, TCPS). ${ }^{[12]}$

The number of adherent cells was also different: significantly more cells adhered on the (PLL-HA) 5 presenting HA of $5.6 \mathrm{kDa}$ when compared to the constructs presenting longer HA chains (Figure 1C). These results clearly demonstrate the distinct effect of the shortest HA $(5.6 \mathrm{kDa})$ on AGS cells: it induces changes in cell morphology, into a spindle-like shape and maintains the high cell proliferation level, as confirmed by Ki-67 staining (Figure S1, Supporting Information).

\subsection{Different Mechanotransduction Induced by the LbL Constructs}

The use of HA with different sizes affect the mechanical properties of the LbL constructs, as previously demonstrated in detail. ${ }^{[13]}$ Cells can sense these differences via a process called mechanotransduction. ${ }^{[14]}$ We measured the surface stiffness of the constructs as a function of the HA's size (AFM nanomechanical mapping) and observed that the shorter HA forms stiffer layers (Figure 2B-C) a result that is consistent with the enhanced hydration capacity of longer HA. ${ }^{[15]}$

Yes-associated protein (YAP) is typically involved in the transduction of mechanical cues. ${ }^{[16]}$ In cancer, the increased expression of YAP together with its nuclear translocation is associated with tumor growth and metastasis. ${ }^{[3,17]}$ We observed that cells cultured on softer surfaces, i.e., (PLL-HA) $)_{5}$ of 618 and $1450 \mathrm{kDa}$, express YAP mainly in the cytoplasm (Figure 2A). YAP translocation to the nucleus occurred in cells seeded on the stiffer surface, i.e., (PLL-HA) 5 of HA $5.6 \mathrm{kDa}$ (Figure S2A, Supporting Information). This translocation is usually associated with the formation of stress fibers that flattens the nucleus to the substrate. ${ }^{[18]}$

Surface stiffness can also modulate the cell's migration pattern. We used time-lapse live cell imaging to determine the cellular paths and distances. AGS cells cultured on stiffer substrates, i.e., TCPS and (PLL-HA) $)_{5}$ containing HA of $5.6 \mathrm{kDa}$ presented the longest cell paths (Figure 2B; Figure S3, Supporting Information). However, the morphology of the cells cultured on these substrates is significantly different as demonstrated by the determined aspect ratio (AR) (Figure 2C; Figure S2B, Supporting Information): round cells were observed on TCPS and (PLL-HA) $)_{5}$ surfaces generated with HA of high $M_{\mathrm{w}}$ (Figure S2C, Supporting Information), while cells with spindle-like morphology was induced by the substrates presenting HA of $5.6 \mathrm{kDa}$ showing that the mechanotransduction is not the only factor that influence this morphological transition. 

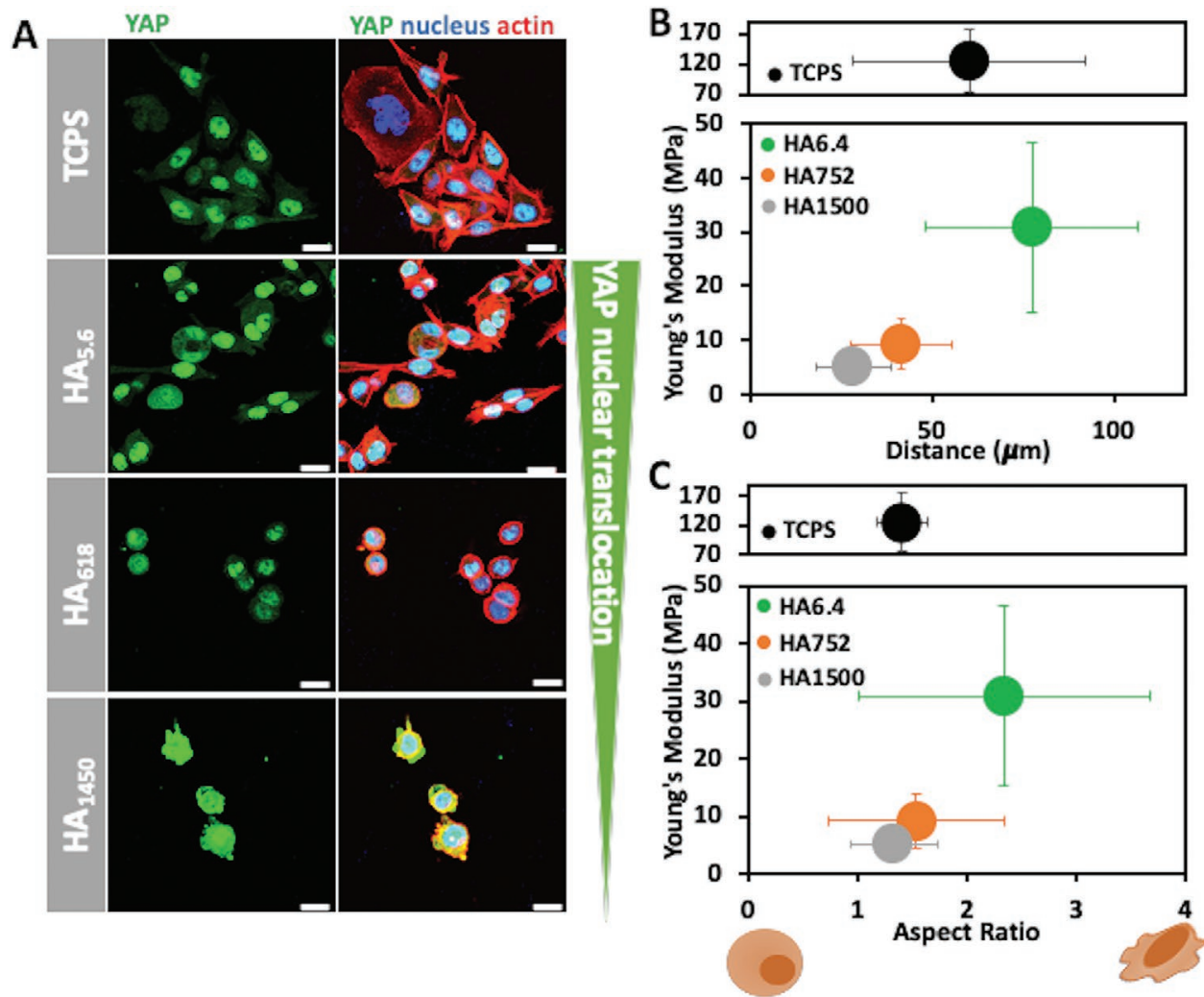

Figure 2. Confocal microscopy images showing the immunofluorescence of YAP protein. Scale bars correspond to $20 \mu \mathrm{m}$ A). Young's modulus versus distance B) and Young's modulus versus aspect ratio C) of AGS cells cultured on LbL constructs presenting HA of different sizes. Data presented in the graphics correspond to the mean \pm SD.

\subsection{HA $M_{\mathrm{w}}$ Modulates the Expression of CD44 and RHAMM Receptors}

CD44, the major cell surface receptor for HA, is a cancer stem cell marker that is overexpressed in GCs. ${ }^{[19]}$ AGS cells cultured on (PLL-HA) $)_{5}$ expressed more CD44 when compared with cells on TCPS and this difference is more pronounced for the constructs containing HA of higher $M_{\mathrm{w}}$ (Figure 3A-C). Such increment of the CD44 expression as a function of the HA size is in good agreement with our previous results obtained with bilayered constructs. ${ }^{[8]}$ Of note, whereas the CD44 protein level increases with the HA $M_{\mathrm{w}}$, the mRNA level shows an opposite trend (Figure 3B). This observation can be explained by: 1) the long protein life-time that gets accumulated over time, while mRNA turnover is fast; and/or 2) mismatch between the mRNA and protein levels, due to the temporal delay between post-translation of mRNA and protein expression. ${ }^{[20]}$

CD44 expressed by AGS cells seeded on TCPS is mainly located in the cytoplasm. When cells are in contact with the substrate containing HA, i.e., LbL constructs, CD44 is recruited to the cells' surface (Figure 3A, white arrows) regardless of the HA size.

RHAMM is another HA receptor that is expressed only during tissue remodeling and in pathological scenarios. As an example, overexpression of RHAMM in cancer promote an invasive phenotype ${ }^{[21]}$ and its colocalization with actin is associated with increased cellular motility. ${ }^{[22]}$ RHAMM can be localized in different cellular compartments and its role depends on the localization: intracellular RHAMM promotes cell polarity and migration, and regulates the microtubule dynamics ${ }^{[23]}$ through the interaction with phosphorylated ERK1/2 protein (i.e., p-ERK1/2), while nuclear RHAMM colocalize with p-ERK1/2, controlling gene expression responsible for cellular motility. ${ }^{[24]}$ Additionally, RHAMM can play different extracellular functions; however, despite its ability to interact with HA, it lacks a link module for HA binding. In this context, RHAMM usually interacts with CD44 to form CD44/RHAMM-HA complexes. Of note, RHAMM present on the cell surface is able to activate HA-dependent signaling pathways associated with cells migration and tumor invasion/ motility through the regulation of Ras, ERK1/2 and Src. ${ }^{[23 b, 25]}$ RHAMM was expressed by AGS cells cultured on different LbLs (Figure 3C; Figure S4A, Supporting Information) but its localization depends on the HA's $M_{\mathrm{w}}$ : AGS cells cultured on (PLL-HA) $)_{5}$ presenting HA of $5.6 \mathrm{kDa}$ have RHAMM localized in the nucleus (Figure $3 \mathrm{~A}$, blue arrows) and in the cytoplasm, while cells cultured on the surfaces presenting HA of 1450 kDa lack nuclear RHAMM (Figure 3A; Figure S4B, Supporting Information). The immunostaining also revealed that AGS cells cultured on LbL with short HA, $5.6 \mathrm{kDa}$, colocalized RHAMM and actin (Figure 3A) and indeed, this is the substrate that promote higher cellular motility (Figure 2B). On 
A
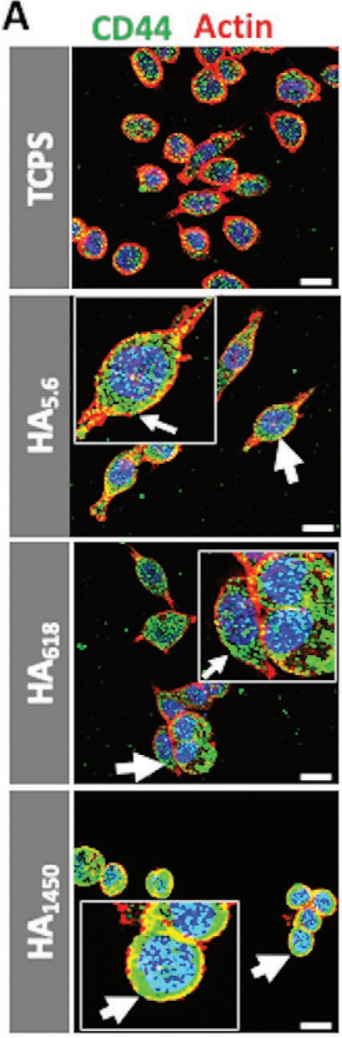

RHAMM Actin
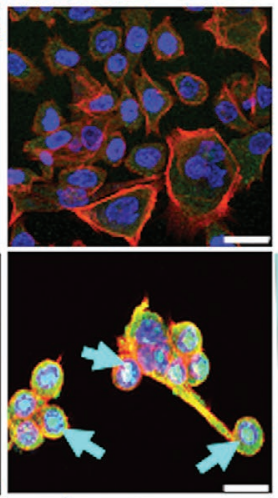
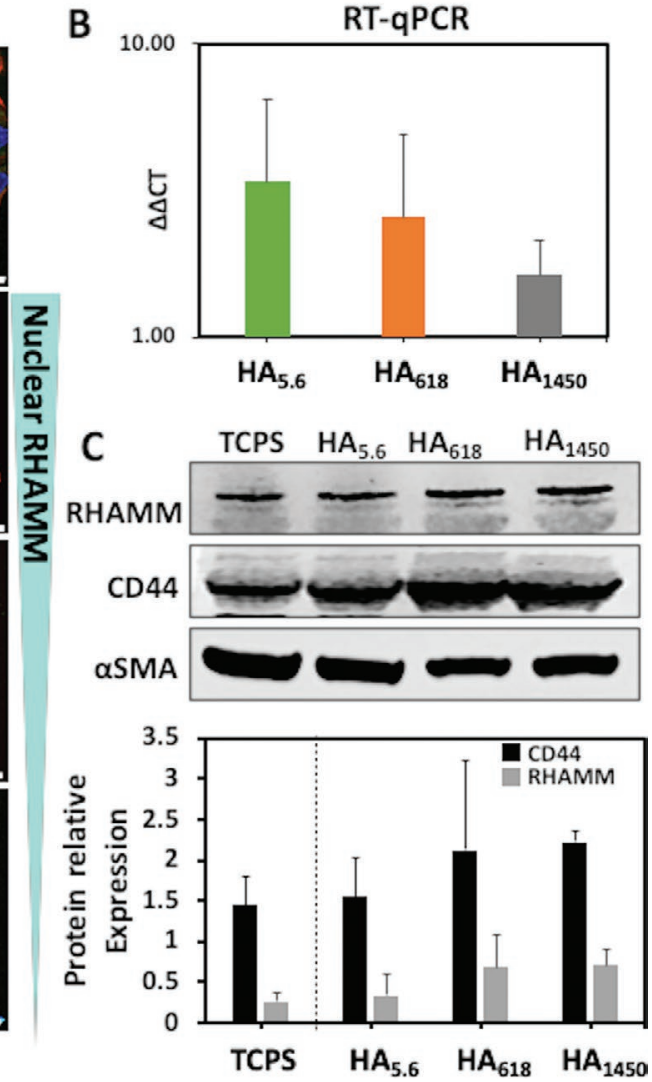

Figure 3. Fluorescence images showing AGS cells cultured on TCPS and (PLL-HA) ${ }_{5}$ of different $M_{w}$ immunostained for CD44 (white arrows indicate CD44 at the membrane) and for RHAMM (blue arrows show nuclear localization of RHAMM). Scale bars correspond to 20 um A). CD44 gene expression on AGS cells seeded on the same LbL surfaces B). Western-blot analysis of CD44 (120 kDa) and RHAMM (90 kDa) after 3 days of cell culture C). The data presented in the graphics correspond to the mean \pm SD and were calculated from a sample size of $n=2$.

the other hand, the nuclear RHAMM and nuclear p-ERK1/2 are present in AGS cells seeded on the same substrates). The proliferation, migration and invasion of cancer cells are often associated with the activation of the ERK1/2 signaling pathway, and their nuclear translocation is a hallmark for cancer aggressiveness, as observed for the surfaces presenting HA of $5.6 \mathrm{kDa} \cdot{ }^{[26]}$

\subsection{HA Regulates the Downstream Signaling Pathways Associated with Cancer Migration}

Tissues infected with $H$. pylori overexpress Annexin 4 (ANX4). [27] ANX4 is a protein predominantly expressed in epithelial cells. Its overexpression is a hallmark of the development of different epithelial tumors, such as the gastric adenocarcinoma. ANX4 is involved in the regulation of downstream signaling cascades, such as the activation of AKT pathway associated with the proliferation and migration of cancer cells as well as with the tumor aggressiveness. ${ }^{[28]}$

AGS cells have high expression of ANX4 as shown by the results obtained for the cells cultured on TCPS (Figure 4). Such high expression is consistent with the malignant phenotype of this cancer cells. A similar observation has been reported to the infected tissues by H. pylori. ${ }^{[29]}$ An inhibition of ANX4 expression and the reduction of the activated form p-AKT was observed in AGS cultures on the LbLs, especially when constructs presenting HA of higher $M_{\mathrm{w}}$, i.e., 618 and $1450 \mathrm{kDa}$ were used as substrates (Figure 4). In contrast, the malignant phenotype associated with the high expression of ANX4 and the p-AKT pathway is maintained on the surfaces presenting HA of $5.6 \mathrm{kDa}$. The overexpression of ANX4 has been reported to be correlated with an upregulation of RHAMM. ${ }^{[30]}$ However, our results show that the increment of the HA's $M_{\mathrm{w}}$ is accompanied by an increase in RHAMM expression both at the protein and mRNA levels (Figure 3C; Figure S4A, Supporting Information). Of note, it is known that CD44 binds to all sizes of HA, while RHAMM preferentially binds to HA of low $M_{\mathrm{w}}$ (i.e., $<7 \mathrm{kDa}$ ). ${ }^{[31]}$ This preferential binding of RHAMM to low $M_{\mathrm{w}}$ HA could be one of the reasons for the maintenance of the malignant phenotype. In fact, we observe the recruitment of RHAMM to the cell's membrane in the presence of HA of $5.6 \mathrm{kDa}$ (Figure S4C, Supporting Information, using nonpermeabilized cells).

Our results are consistent with a dual effect of HA on the invasiveness of GC, under HA's size-mediated pathways. The HA of $5.6 \mathrm{kDa}$ recruits CD44 to the cell surface and stimulates the synthesis of de novo CD44, which could be associated with the stemness behavior of AGS cells. In addition, the presence of 

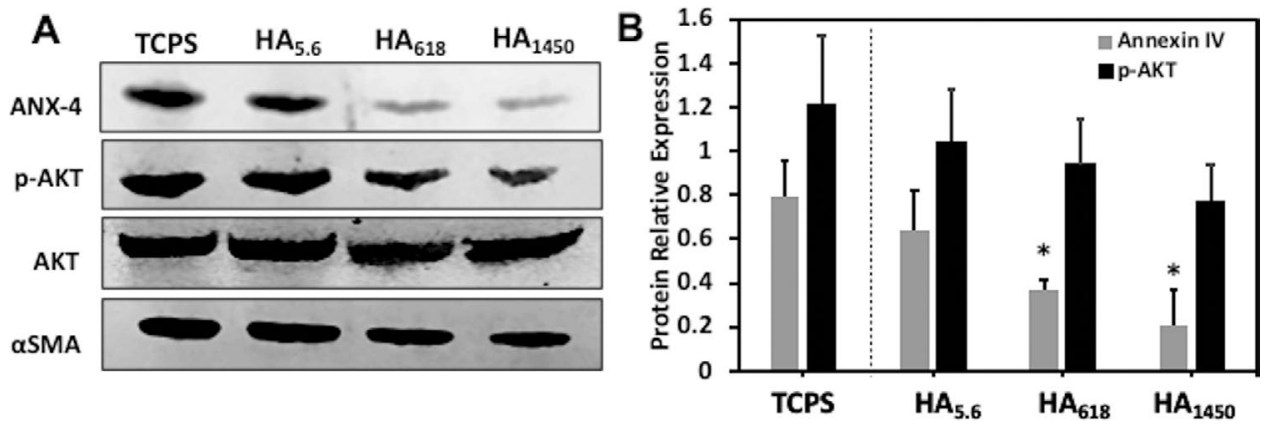

Figure 4. Western-blot analysis and the respective densitometry showing the expression of ANX4 (35 kDa) and p-AKT (62 kDa) by the ACS cells cultured on the different LbLs. The data presented in the graphics correspond to the mean \pm SD and were calculated from a sample size of $n=3$. Statistical significance was calculated using the Mann-Whitney test. Statistically differences are marked for $p<0.05$, in comparison to the control (TCPS).

RHAMM in the cell membrane could be correlated to the formation of CD44/RHAMM-HA complexes with HA of $5.6 \mathrm{kDa}$ triggering the elongated shape which is characteristic for invasive cells and agrees with the protein expression of p-ERK1/2, ANX4, and p-AKT confirming the invasive phenotype of these cells. ${ }^{[4 a]}$ In contrast, long HA (of $1450 \mathrm{kDa}$ ) recruits CD44 to the cell surface but does not trigger de novo CD44 synthesis. In addition, an inhibition of ANX4 accompanied by a reduced expression of $p$-AKT is also observed (Figure 4B). AGS attachment to (PLL-HA) $)_{5}$ containing $\mathrm{HA}$ of $1450 \mathrm{kDa}$ induces a decreased migration, while invasive pathways are downregulated, being consistent with a promotion of cancer latency by long HA (Figure 5). ${ }^{[31]}$

\section{Conclusion}

We demonstrated that HA of different sizes can induce distinct cancer cell behavior. AGS GC cells displayed increased polarity and morphometric changes associated with the invasive "hummingbird" phenotype in the presence of short HA, i.e., $5.6 \mathrm{kDa}$. We further demonstrated that long HA, i.e., HA of

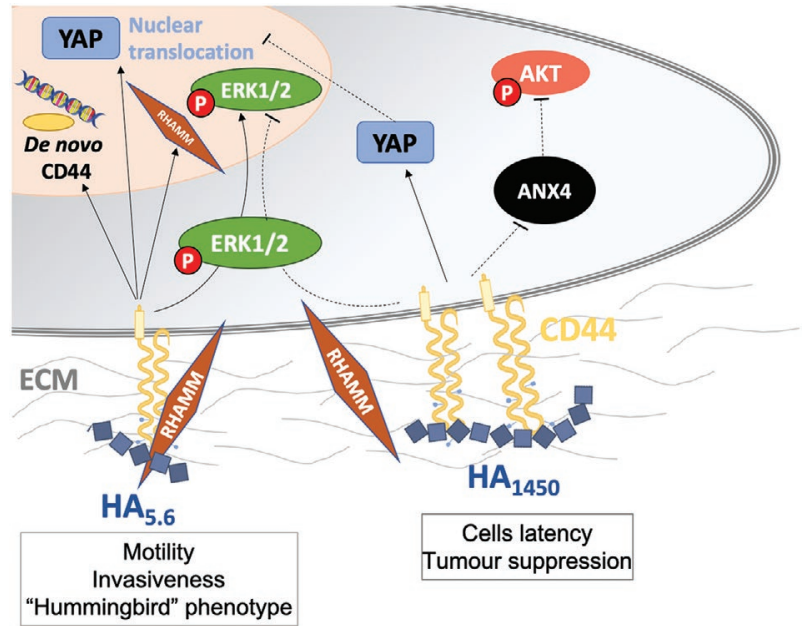

Figure 5. Schematic representation of the proposed mechanisms (and signaling pathways) promoted by the HA of different $M_{\mathrm{w}}$.
$1450 \mathrm{kDa}$, inhibits the migration of AGS cells, being consistent with the promotion of less migrating cell phenotype. In conclusion, we show that the developed LbL surfaces are relevant model systems that can be used to study cancer cell behavior, in particular the different signaling cascades involved in HAmediated cancer cell migration and invasion.

\section{Experimental Section}

Materials: HA sodium salts of $5.6 \mathrm{kDa}, 618 \mathrm{kDa}$ (HA700K-5), and $1450 \mathrm{kDa}$ (HA15M-5) ( $M_{\mathrm{w}}$ was determined by GPC as detailed below) were purchased from Lifecore (USA) and poly-L-lysine (PLL) hydrobromide (P2636) was acquired from Sigma-Aldrich. N-(3Dimethylaminopropyl)- $N^{\prime}$-ethylcarbodiimide hydrochloride (EDC, $\geq 98.0 \%$ ) and $\mathrm{N}$-hydroxysuccinimide (NHS) were purchased from SigmaAldrich. The reagents were used as received without further purification.

Gel Permeation Chromatography (GPC): GPC measurements were performed using a Malvern Viscotek TDA 305 with refractometer (RI-Detector 8110, Bischoff), right and low angle light scattering (LS), and viscometer detectors on a set of four columns: precolumn Suprema, $5 \mu \mathrm{m}, 8 \times 50$, Suprema $30 \AA, 5 \mu \mathrm{m}, 8 \times 300$, and $2 x$ Suprema $1000 \AA$, $5 \mu \mathrm{m} 8 \times 300$. The system was kept at $30^{\circ} \mathrm{C}$. PBS buffered saline $(0.01$ $\mathrm{M}$ phosphate buffer, $0.0027 \mathrm{M}$ potassium chloride and $0.137 \mathrm{M}$ sodium chloride, $\mathrm{pH} 7.4$, at $25{ }^{\circ} \mathrm{C}$, Sigma-Aldrich) and $0.05 \%(\mathrm{w} / \mathrm{v}) \mathrm{NaN}_{3}$ were used at a rate of $1 \mathrm{~mL} \mathrm{~min}{ }^{-1}$. The absolute $M_{w}$ was determined by a calibration of the RI and LS detectors performed using the software Omnisec 5.12 (ViskoteK) with a pullulan of $M_{n} 48.8 \mathrm{kDa}$ and PDI 1.07. The $\mathrm{dn} / \mathrm{dc}$ of HA was taken from the literature. ${ }^{[32]}$ The chromatograms are presented in Figure S6 (Supporting Information).

Layer-by-Layer Film Construction: The LbL constructs were build-up on tissue culture polystyrene (TCPS) coverslips of $13 \mathrm{~mm}$ diameter by alternate dipping, for $10 \mathrm{~min}$, into a solution of PLL $\left(0.5 \mathrm{mg} \mathrm{mL}^{-1}\right.$ in $\mathrm{NaCl} 0.15 \mathrm{M}$ ) and in a solution of $\mathrm{HA}\left(1 \mathrm{mg} \mathrm{mL}^{-1}\right.$ in $\left.\mathrm{NaCl} 0.15 \mathrm{M}\right)$ containing the crosslinker EDC $\left(400 \times 10^{-3} \mathrm{M}\right)$ and NHS $\left(100 \times 10^{-3} \mathrm{M}\right)$. After each layer deposition, the substrate was washed for $10 \mathrm{~min}$ with $\mathrm{NaCl} 0.15 \mathrm{M}$ at $\mathrm{pH} \approx 6.0-6.5$. The sequential layer deposition was repeated ten times generating a $(\mathrm{PLL}-\mathrm{HA})_{5}$ film. The final constructs were washed with water and sterilized under UV light for 30 min prior cell seeding.

Cell Seeding and Immunocytochemistry Analysis: AGS cells (a hyperdiploid middling differentiated human gastric adenocarcinoma cell line derived from a tumor resected from the stomach of a 54 year old Caucasian female), at passage 6, were expanded in RPMI-1640 medium (Sigma-Aldrich, Portugal) supplemented with $10 \%$ of fetal bovine serum (FBS, Gibco) and 1\% antibiotic/antimycotic solution (final concentration of penicillin 100 units $\mathrm{mL}^{-1}$, streptomycin $100 \mathrm{mg} \mathrm{mL}^{-1}$ and $25 \mu \mathrm{g} \mathrm{mL}$ amphotericin B; Gibco, UK) and incubated at $37{ }^{\circ} \mathrm{C}$ in the presence of 
Table 1. Sequences of the CD44 and RHAMM PCR primers.

\begin{tabular}{|c|c|c|}
\hline & Forward primer & Reverse primer \\
\hline CD44 & 5'-CGCAGCCTGGGGACTCTG-3' & 5'-CGAGAGATGCTGTAGCGACCA-3' \\
\hline RHAMM & $5^{\prime}$-TTGCCCTCAACACCCCATT- $3^{\prime}$ & 5'-TGTTCCTTTCACATATTTAAGCATTG- $3^{\prime}$ \\
\hline
\end{tabular}

$5 \% \mathrm{CO}_{2}$ until reaching confluence. Cells were harvested with TrypLE and seeded (11 000 cells $\mathrm{cm}^{-2}$ ) on the TCPS (control) and (PLL-HA) coated TCPS for 3 days. For immunostaining, cells were washed with PBS, fixed with $10 \%$ buffered formalin, followed by permeabilization with $0.2 \%$ Triton X-100 in PBS for 5 min. Cells were blocked with 3\% BSA in PBS for $30 \mathrm{~min}$ at room temperature and the monoclonal antibody to CD44 (AM06286SU-N from ACRIS) was used at a 1:400 dilution in 1\% BSA in PBS (w/v) for $1 \mathrm{~h}$ at room temperature. The rabbit antimouse Alexafluor-488 (1:500 dilution, 1\% BSA in PBS (w/v)) was used as a secondary antibody. For the staining of nuclei and actin, DAPI (1:500 dilution in 1\% BSA in PBS $(\mathrm{w} / \mathrm{v})$ ) and Phalloidin-TRITC (1:250 dilution, $1 \%$ BSA in PBS (w/v)) were used, respectively. RHAMM was stained with RHAMM ( $\mathrm{H}-8)$ mouse monoclonal antibody (1:400 dilution) and for YAP a human antimouse antibody was employed (SC-101199; 1:500 dilution, $1 \%$ BSA in PBS), followed by the secondary rabbit antimouse Alexafluor-488 (1:500 dilution, 1\% BSA in PBS) for both primary antibodies. Stained cells were observed under confocal laser scanning microscope (TCS SP8, Leica, Germany).

Real-Time aPCR: Total RNA was extracted from ACS cells seeded on $(\mathrm{PLL}-\mathrm{HA})_{5}$ coated T25 culture flasks. Briefly, after 3 days of culture the flasks were washed with PBS, the TRI reagent (Sigma-Aldrich, USA) was added, and the flask was gently scratched to remove the cells from the bottom. The cells were stored at $-80^{\circ} \mathrm{C}$. After the removal of proteins by chloroform extraction, the RNA pellet was washed with isopropyl alcohol and ethanol (70\%). The RNA pellet was rebuilt in RNAse-free water (Gibco, Invitrogen, UK). Reverse transcriptase (RT)-PCR was performed according to the protocol from the iScript cDNA synthesis kit (QuantaBio, Gaithersburg, MD, USA). The transcripts' expression data were normalized with the housekeeping gene $18 \mathrm{~S}$ and the relative quantification calculated according to the Livak $\left(2 \_\Delta \Delta C T\right)$ method using the cells seeded on TCPS as the calibrator. The CD44 (all isoforms) and RHAMM gene expression was evaluated using the primers presented in Table 1.

Cells Migration through Time-Lapse Analysis: After $24 \mathrm{~h}$ of incubation, the cells seeded on the different surfaces were analyzed using an inverted microscope (Zeiss Axio Observer, Germany) equipped with a temperature $\left(37^{\circ} \mathrm{C}\right)$ and $\mathrm{CO}_{2}$ control device $\left(5 \% \mathrm{CO}_{2}\right)$. Images of the cells (20X objective) were continuously captured every 5 min for $16 \mathrm{~h}$ using the Zen software (Zeiss, Germany). Image stacks and cellular displacement were analyzed with the Fiji software (http://fiji.sc/wiki/ index.php/Fiji) using the Manual Tracking Plugin.

Western-Blot Analysis: AGS protein lysates were extracted in RIPA buffer $\left(150 \times 10^{-3} \mathrm{M} \mathrm{NaCl}, 1 \%\right.$ Triton-X100, $0.5 \%$ sodium deoxycholate, $0.1 \%$ sodium dodecyl sulphate, $50 \times 10^{-3} \mathrm{M}$ Tris-Base, $\mathrm{pH}=8$ ) supplemented with 1x Protease (cOmplete, ROCHE) and 1x Phosphatase (PhosSTOP, ROCHE) inhibitor cocktails for 30 min with 5 min intervals of vortexing. The extracts were centrifuged $\left(18000 \times \mathrm{g}, 16 \mathrm{~min}, 4^{\circ} \mathrm{C}\right)$, and the supernatant was further analyzed by Western-blotting. The proteins in the Laemmli buffer were denatured at $37^{\circ} \mathrm{C}$ for $1 \mathrm{~h}$ and $30 \mathrm{~min}$ and 95 ${ }^{\circ} \mathrm{C}$ for $5 \mathrm{~min}$ prior to use. The lysates containing $40 \mu \mathrm{g}$ of protein were resolved using 4-12\% Bis-Tris Protein Gels (Novex) and transferred to nitrocellulose membranes (Thermo Fischer Scientific). The membranes were incubated in $4 \%(\mathrm{~m} / \mathrm{v})$ BSA in Tris-buffered saline-Tween (TBS-T, Cell Signalling Technology) and probed with $\alpha$-smooth muscle actin (rabbit monoclonal [E184], 1:5000 dilution), p-AKT (rabbit monoclonal antibody [EP2109Y], 1:1000 dilution), AKT (rabbit monoclonal antibody (B-1), 1:1000 dilution), RHAMM (mouse monoclonal antibody (H-8), 1:1000 dilution), $\mathrm{p}$-ERK1/2 (rabbit monoclonal antibody, 1:1000 dilution), CD44 (rabbit monoclonal antibody, 1:1000 dilution), and Annexin-4 (rabbit monoclonal antibody, 1:1000 dilution). After three cycles of
5 min washing with TBS-T, the membranes were incubated with IRDye800CW antirabbit or antimouse (1:10000 dilution) for $1 \mathrm{~h}$ and imaged on the Odyssey Infrared Imaging System (LI-COR Biosciences).

Statistical Analysis: The data were graphically presented as mean $\pm \mathrm{SD}$ and the statistical analysis was performed for a sample size $(n)$ $\geq 3$. The Shapiro-Wilk test was used to evaluate the normality of the distribution of the data $(p<0.05)$. The Kruskal-Wallis test followed by the Mann-Whitney test was applied when the data showed non-normal distribution. Significant variations are considered with $* * *$ for $p<$ 0.001 , $* *$ for $p<0.01$, and $*$ for $p<0.05$. Graphical representation and statistical analysis were performed on GraphPad Prism 7.0 Software.

\section{Supporting Information}

Supporting Information is available from the Wiley Online Library or from the author.

\section{Acknowledgements}

The authors acknowledge the financial support from the European Commission's H2020 Programme, under grant agreements H2020WIDESPREAD-2014-668983-FORECAST and H2020-MSCA-RISE-2019872648-MEPHOS. S.A. acknowledge the Portuguese Foundation for Science and Technology (FCT) for the PhD grant (SFRH/ BD/112075/2015). The authors also thank Ramon Novoa-Caballal for performing the GPC experiments and data analysis.

\section{Conflict of Interest}

The authors declare no conflict of interest.

\section{Keywords}

cancer invasiveness, hummingbird, hyaluronic acid, molecular weight

Received: May 5, 2020

Revised: September 2, 2020

Published online:

[1] P. Diaz, M. Valenzuela Valderrama, J. Bravo, A. F. G. Quest, Front. Microbiol. 2018, 9, 5.

[2] L. E. Wroblewski, R. M. Peek, Jr., K. T. Wilson, Clin. Microbiol. Rev. 2010, 23, 713

[3] N. Li, Y. Feng, Y. Hu, C. He, C. Xie, Y. Ouyang, S. C. Artim, D. Huang, Y. Zhu, Z. Luo, Z. Ge, N. Lu, J. Exp. Clin. Cancer Res. 2018, 37, 280.

[4] a) K. M. Bourzac, C. M. Botham, K. Guillemin, Infect. Immun. 2007, 75, 1203; b) M. Hatakeyama, Int. J. Cancer 2006, 119, 1217; c) D. B. Polk, R. M. Peek, Jr., Nat. Rev. Cancer 2010, 10, 403; d) C. Figueiredo, M. A. Garcia-Gonzalez, J. C. Machado, Helicobacter 2013, 18, 28. 
[5] a) E. Bessede, C. Staedel, L. A. Acuna Amador, P. H. Nguyen, L. Chambonnier, M. Hatakeyama, G. Belleannee, F. Megraud, C. Varon, Oncogene 2014, 33, 4123; b) C. C. Chang, W. S. Kuo, Y. C. Chen, C. L. Perng, H. J. Lin, Y. H. Ou, PLoS One 2016, 11, e0150061.

[6] a) H. Baba, H. Okabe, K. Mima, S. Saito, H. Hayashi, K. Imai, H. Nitta, D. Hashimoto, A. Chikamoto, T. Ishiko, T. Beppu, J. Cancer Metastasis Treatment 2015, 1, 183; b) M. S. Marques, J. Melo, B. Cavadas, N. Mendes, L. Pereira, F. Carneiro, C. Figueiredo, M. Leite, Front. Microbiol. 2018, 9, 2712.

[7] a) M. Yu, P. He, Y. Liu, Y. He, Y. Du, M. Wu, G. Zhang, C. Yang, F. Gao, Med. Oncol. 2015, 32, 381; b) S. Matou-Nasri, J. Gaffney, S. Kumar, M. Slevin, Int. J. Oncol. 2009, 35, 761.

[8] S. Amorim, D. Soares da Costa, D. Freitas, C. A. Reis, R. L. Reis, I. Pashkuleva, R. A. Pires, Sci. Rep. 2018, 8, 16058.

[9] a) N. Bertaux-Skeirik, R. Feng, M. A. Schumacher, J. Li, M. M. Mahe, A. C. Engevik, J. E. Javier, R. M. Peek, Jr., K. Ottemann, V. OrianRousseau, G. P. Boivin, M. A. Helmrath, Y. Zavros, PLoS Pathog. 2015, 11, e1004663; b) S. Mereiter, A. M. Martins, C. Gomes, M. Balmana, J. A. Macedo, K. Polom, F. Roviello, A. Magalhaes, C. A. Reis, FEBS Lett. 2019, 593, 1675; c) I. B. Moreira, F. Pinto, C. Gomes, D. Campos, C. A. Reis, Cells 2020, 9, 264.

[10] K. T. Dicker, L. A. Gurski, S. Pradhan-Bhatt, R. L. Witt, M. C. FarachCarson, X. Jia, Acta Biomater. 2014, 10, 1558.

[11] S. Schneider, C. Weydig, S. Wessler, Cell Commun. Signaling 2008, $6,2$.

[12] K. Iwakura, H. Wu, T. Nakano, E. Daikoku, C. Shimamoto, K. Katsu, K. Sano, Bull OMC 2007, 53, 1.

[13] S. Amorim, I. Pashkuleva, C. A. Reis, R. L. Reis, R. A. Pires, J. Mater. Chem. B 2020, 8, 3880

[14] M. Cantini, H. Donnelly, M. J. Dalby, M. Salmeron-Sanchez, Adv. Healthcare Mater. 2020, 9, e1901259.

[15] M. K. Cowman, T. A. Schmidt, P. Raghavan, A. Stecco, F1000Research 2015, 4, 622

[16] I. Dasgupta, D. McCollum, J. Biol. Chem. 2019, 294, 17693.

[17] X. Zhang, A. Abdelrahman, B. Vollmar, D. Zechner, Int. J. Mol. Sci. 2018, 19, 3770.

[18] A. Elosegui-Artola, I. Andreu, A. E. M. Beedle, A. Lezamiz, M. Uroz, A. J. Kosmalska, R. Oria, J. Z. Kechagia, P. Rico-Lastres, A. L. Le Roux, C. M. Shanahan, X. Trepat, D. Navajas, S. Garcia-Manyes, P. Roca-Cusachs, Cell 2017, 171, 1397.
[19] a) S. Misra, P. Heldin, V. C. Hascall, N. K. Karamanos, S. S. Skandalis, R. R. Markwald, S. Ghatak, FEBS J. 2011, 278, 1429; b) T. Ishimoto, H. Baba, Gastrointest. Cancer: Targets Ther. 2014, 4, 123.

[20] K. Becker, A. Bluhm, N. Casas-Vila, N. Dinges, M. Dejung, S. Sayols, C. Kreutz, J. Y. Roignant, F. Butter, S. Legewie, Nat. Commun. 2018, 9, 4970.

[21] a) J. Entwistle, C. L. Hall, E. A. Turley, J. Cell. Biochem. 1996, 61, 569; b) V. Mele, L. Sokol, V. H. Kolzer, D. Pfaff, M. G. Muraro, I. Keller, Z. Stefan, I. Centeno, L. M. Terracciano, H. Dawson, I. Zlobec, G. lezzi, A. Lugli, Oncotarget 2017, 8, 70617.

[22] V. Assmann, D. Jenkinson, J. F. Marshall, I. R. Hart, J. Cell Sci. 1999, 112, 3943.

[23] a) A. Muroyama, T. Lechler, Development 2017, 144, 3012; b) C. A. Maxwell, J. McCarthy, E. Turley, J. Cell Sci. 2008, 121, 925.

[24] a) S. Misra, V. C. Hascall, R. R. Markwald, S. Ghatak, Front. Immunol. 2015, 6, 201; b) C. Tolg, J. B. McCarthy, A. Yazdani, E. A. Turley, Biomed Res. Int. 2014, 2014, 103923.

[25] S. R. Hamilton, S. F. Fard, F. F. Paiwand, C. Tolg, M. Veiseh, C. Wang, J. B. McCarthy, M. J. Bissell, J. Koropatnick, E. A. Turley, J. Biol. Chem. 2007, 282, 16667.

[26] a) A. Plotnikov, K. Flores, G. Maik-Rachline, E. Zehorai, E. KapriPardes, D. A. Berti, T. Hanoch, M. J. Besser, R. Seger, Nat. Commun. 2015, 6, 6685; b) M. Olea-Flores, M. D. Zuñiga-Eulogio, M. A. Mendoza-Catalán, H. A. Rodríguez-Ruiz, E. CastañedaSaucedo, C. Ortuño-Pineda, T. Padilla-Benavides, N. Navarro-Tito, Int. J. Mol. Sci. 2019, 20, 2885.

[27] L. L. Lin, C. N. Chen, W. C. Lin, P. H. Lee, K. J. Chang, Y. P. Lai, J. T. Wang, H. F. Juan, Proteomics: Clin. Appl. 2008, 2, 619.

[28] a) W. Chen, L. Chen, Z. Cai, D. Liang, B. Zhao, Y. Zeng, X. Liu, J. Liu, Tumour Biol. 2016, 37, 9343; b) T. Mogami, N. Yokota, M. Asai-Sato, R. Yamada, S. Koizume, Y. Sakuma, M. Yoshihara, Y. Nakamura, Y. Takano, F. Hirahara, Y. Miyagi, E. Miyagi, PLoS One 2013, 8, e80359; c) H. Yao, C. Sun, Z. Hu, W. Wang, Front. Biosci. 2016, 21, 949.

[29] B. Wei, C. Guo, S. Liu, M. Z. Sun, Clin. Chim. Acta 2015, 447, 72.

[30] L.-L. Lin, H.-C. Huang, S. Ogihara, J.-T. Wang, C.-N. Chen, H.-F. Juan, Nat. Prec. 2010, https://doi.org/10.1038/npre.2010.4887.1.

[31] M. Liu, C. Tolg, E. Turley, Front. Immunol. 2019, 10, 947.

[32] Y. Han, D. Li, D. Li, W. Chen, S. E. Mu, Y. Chen, J. Chai, Sci. Rep. 2020, 10, 1858 